\title{
Importancia de las políticas públicas en el desarrollo complejo de la sociedad contemporánea
}

\author{
Uvalle Berrones, Ricardo*
}

\section{Resumen}

El artículo analiza y explica la relevancia de las políticas públicas con base en la democratización del poder, la recuperación del espacio público, el declive de las estructuras administrativas centralizadas y el significado de la gobemabilidad democrática, situación que implica fortalecer los métodos de buen gobiemo para atender y solucionar con eficacia los asuntos públicos. El tiempo de los gobiernos omnipresentes ha llegado a su fin, motivo por el cual, los procesos de gobernabilidad tienen que fortalecerse tomando en cuenta la pluralidad y diversidad de los actores sociales y politicos. Por ello, gobernar por políticas es un imperativo para nutrir la institucionalidad democrática, la cual acredita los modos, tiempos, recursos, estrategias y resultados que permiten atemperar los conflictos que son ordenados y procesados de acuerdos a la agenda institucional.

Palabras clave: Políticas públicas, Gobernabilidad, sociedad contemporánea, Democracia, Espacio público.

\section{The Importance of Public Policy in the Complex Development of Contemporary Society}

\begin{abstract}
This article analyzes and explains the relevance of public policy oriented towards the democratization of power, the recovery of public space, the decline of centralized administrative structures, and the significance of democratic governability. This is an orientation which implies

Recibido: 01-03-21, Aceptado: 01-05-07

Doctor en Administración Pública (UNAM). Profesor de tiempo completo Facultad de Ciencias Políticas y Sociales de la UNAM en la licenciatura y el postgrado en Administración Pública investigador reconocido de por el Consejo Nacional de Ciencias Tecnología y la Secretaría de Educación Pública. Autor de diversos libros y artículos en materia de gobierno y administración pública. Conferencista en congresos, paneles y seminarios nacionales e internacionales.

E-mail: helmut $@$ avantel.net.
\end{abstract}


strengthening methods of good government in order to deal with and solve public matters efficiently. The era of omni-present government is over, and for this reason the processes of governability have to be strengthened taking into account the plurality and diversity of political and social actors. To do this, it is imperative to govern by policy in order to strengthen democratic institutionality which assures the manner, mornent, resources, strategies and results which allow for resolving conflicts which are ordered and processed according to an institutional agenda.

Key words: Public policy, govemability, contemporary society, democracy, public space.

\section{Contexto}

Las condiciones económicas y sociales del mundo actual dan cuenta de procesos que se traducen en avances que modifican las principales variables de los sistemas sociales y políticos. La existencia de la economia monetaria, el avance de los mercados y la innovación tecnológica de punta, configuran un panorama competitivo en una sociedad que, como la contemporánea, da cauce a los ritmos y tiempos que alientan los movimientos de la riqueza material, teniendo como medios fundamentales el comercio y las inversiones financieras.

En los marcos de una nueva civilización- desarrollo de la electrónica, aumento de la incertidumbre y la sociedad del conocimiento aplicado- la economía de mercado tiene otros senderos de realización. El valor de la moneda en sí mis$\mathrm{ma}$, esto es, sin estricta relación con el plusvalor industrial, es uno de los aspectos más importantes que dan vida a las relaciones económicas que tienen como base el dinero. Las operaciones del intercambio económico se realizan fundamentalmente con actividades relacionadas a la fusión de empresas y bancos; las acciones de las bolsas, la digitalización del dinero; el auge de los mercados de capital; el movimiento de las tasas de interés y los portafolios de inversión.

Esta situación configura escenarios distintos a la sociedad moderna-previsión, regularidad y certidumbre-, lo cual implica que las organizaciones públicas y privadas han ingresado a otros tiempos de riesgo y competencia; de lucha y reacomodo; de articulación y producción de nuevas capacidades. La cultura del mercado es el detonador para situar los cambios que se efectúan en las condiciones de vida dadas en el tiempo de la globalidad. Es una cultura empredendora e innovativa que conduce a que las esferas microindividual y macrosocial se rearticulen en razón de nuevas tecnologías, procesos y sistemas de gestión. Es el conocimiento fáctico, la base para que los mercados consigan avanzar con rapidez. Pero es el conocimiento básico, el medio efectivo para vislumbar los nuevos horizontes que caracterizan a la sociedad actual, tomando en cuenta los retos y las oportunidades del mercado, entendido como un lugar que tiene alcance público y para el público.

La cultura del mercado no resume en sí los valores del utilitarismo ni las ganancias insensibles; en todo caso, reconoce y recompensa el riesgo; alienta lo empresarial, teniendo como eje que la 
competencia es el acicate que permite ganar, reinvertir, multiplicar y consolidar. Es una cultura de riesgos individuales o compartidos; no es una cultura opuesta a las ventajas comparativas. Dicha cultura es un sistema de valores que posibilita la realización individual y colectiva.

Lo individual se reconoce porque las capacidades de cada persona son la riqueza más valiosa para emprender las actividades productivas. Lo colectivo es suma de esfuerzos para aprovechar tiempos, recursos e iniciativas que contribuyen a fortalecer la vida de la sociedad y los mercados, teniendo como punto cardinal las ventajas y los beneficios de carácter público. Los valores de la cultura del mercado responden a la sociedad emprendedora y no se identifican de manera mecánica con los aspectos de orden económico y monetario. Este planteamiento es opuesto al paradigma de la equidad y la eficiencia que postula el mundo laico, moderno y secular, el cual articula los principios de libertad, democracia y justicia para dar vigencia a la sociedad abierta y el Estado de derecho.

Por tal motivo, la cultura del mercado ha sido y continua siendo un factor central en las transformaciones de la vida social. La sociedad actual es producto de una nueva civilización; en este caso, de la civilización que se desarrolla con base en el caos, las inestabilidades, las aperturas externas y el predominio de la cultura del mercado. La civilización contemporánea, entendida en los valores de la cultura del mercado, conjuga la filosofía del cambio progresivo, la innovación continua y la renovación en gran escala. Por eso, el tránsito de lo holístico a lo local; de la centralización a la descentralización; del colecti- vismo a lo individual; de las sociedades tribales a las sociedades abiertas (Popper, 1993: 171); de la dicotomía mercado - Estado a la cooperación Estado mercado; de la política burocrática a la política democrática; de la administración estatizada a la ciudadanización de los gobiernos, de la planeación central a las políticas públicas, son capítulos que modifican las relaciones entre las instituciones públicas y la vida privada.

En la civilización contemporánea (Giddens, 1993: 130), la ruta de la certeza cede su lugar a la senda de la incertidumbre. En ésta lógica, se estructuran otros espacios de cooperación que trascienden a los Estados y los gobiernos. Uno es el mercado, entendido como un sistema de cooperación social que permite no sólo producir y distribuir mercancías, sino vincular capacidades diferenciadas para garantizar que la sociedad y la economía tengan los elementos indispensables de convivencia y desarrollo. Otro es el espacio público, entendido no como la agregación de voluntades particulares, sino como un sistema de vida que, a partir de identidades, organización y compromisos, favorecen que la sociedad tenga mayores ámbitos de realización y creatividad. Uno más es la esfera privada, la cual se integra por personas que tienen conciencia, preferencias, voluntad y deseos para alcanzar fines lícitos y legítimos para tener un lugar en la competitividad de la sociedad contemporánea. Los espacios de cooperación no son coyunturales, responden a la esencia de que no hay monopolios ni cotos de acción que sean exclusivos e impenetrables. Los espacios de cooperación son el pilar que garantiza a las relaciones económicas y sociales te- 
ner un desenvolvimiento fructífero. Son espacios que tienen dinamismo propio, susceptible de multiplicarse hasta conseguir que la sociedad tenga condiciones favorables de vida.

Para tal efecto, la configuración de los sistemas sociales y económicos no debe vislumbrarse a partir de "leyes" o determinismos históricos. Tal concepción es atemporal porque se apoya en ópticas que sitúan a las sociedades como un cuerpo de átomos, es decir, carente de vida propia. Esta imprecisión da lugar a que la sociedad sea considerada distante de sus propios valores, hasta caer en posiciones maníqueas que la enfrentan con sus propias instituciones; en este caso, el mercado y las acciones públicas.

Una postura que ha contribuido a está situación, es el uso de la categoría sociedad civil, la cual no es funcional para situar la trascendencia de los tiempos actuales- crisis, cambios, transformación, reformas - que son de creciente intensidad. La misma, es decir, la sociedad civil, es una categoría que refiere a lo formal, lo abstracto y lo general. Se restringe su aplicación al ámbito estrictamente económico o político, sin aludir a las formas de cooperación que se forman con sentido público. Por ello, la lógica del mercado se valora como "atentatoria", porque se visualiza como parte del oleaje economicista, no como un sistema abierto y competitivo de vida.

De este modo, la categoría sociedad de mercado es más funcional para situar el mundo de la globalidad y las aperturas, destacando la misión que le corresponde desempeñar a los gobiernos. La sociedad de mercado denota la complejidad de los esfuerzos, las iniciativas y los proyectos que compiten entre sí para ganar sitios importantes en la economía y la vida social. La sociedad de mercado combina valores, instituciones y recursos que son necesarios para asegurar la producción de los valores de uso y cambio, teniendo como sustento normas, criterios, reglas y procesos que facilitan su distribución ordenada en favor de la vida pública y la vida privada.

La sociedad de mercado ha recuperado espacios y con base en la globalidad, tiende a que lo individual, lo público y lo local sean los centros fundamentales del quehacer colectivo. La sociedad de mercado es el arquetipo de un mundo abierto e interdependiente que modifica los patrones de vida, tendiendo como referente la cooperación interinstitucional. La sociedad de mercado se nutre de realidades económicas, tecnológicas, políticas y culturales que indican que los nuevos derroteros apuntan por la aceleración del tiempo contemporáneo y por la complejidad creciente de los procesos que denotan la apertura de estructuras, la dinámica de los actores y las acciones que se ordenan a partir de los esfuerzos públicos y privados.

\section{El declive del Estado administrativo}

En el tiempo actual, los sistemas verticales, centralistas, burocratizados $y$ autoritarios han ingresado a zona de crisis, deterioro y estancamiento. Se encuentran en el ocaso de su eficacia, dado que giran en su propio eje y se encuentran distantes del dinamismo y la organización ciudadana. El peso y la longevidad de los grandes aparatos del poder son antifun- 
cionales cuando los movimientos ciudadanos reclaman un lugar en los procesos de la política y las políticas, los cuales son la clave para situar la relación directa entre los ciudadanos y los gobiernos.

En uno y otro caso, las burocracias densas, sobredilatadas y multiplicadas pierden capacidad de respuesta. Reaccionan con lentitud y cierran los espacios para que las acciones ciudadanas tengan receptividad en las esferas de la decisión y en la implementación de los programas públicos. Además, tienden a la improductividad porque la variedad de las respuestas institucionales que formulan son de carácter inercial y ordinario, cuando en el ámbito de los ciudadanos se reclama la eficacia gubemamental para combinarla con la participación social y las ventajas compartidas. La estructura de los aparatos burocráticos se sustenta en valores, prácticas y códigos que estimulan el ejercicio centralizado del poder. Dicha situación se incrementa cuando las costumbres administrativas y la cultura piramidal consiguen traducirse en un sistema de vida que llega a tener legitimidad significativa.

La arquitectura de los aparatos burocratizados y estatales no es eficaz para los reclamos de la democratización. Ésta implica redistribución del poder; del poder que se organiza en la sociedad y que se deposita en los gobiernos. Para los fines de la democratización, los rituales y las reglas de los aparatos centralizados impiden la formulación de políticas oportunas; de las que contribuyen a la atención y solución de los problemas públicos, tomando en cuenta la pluralidad de las demandas y la acción organizada de los grupos que exigen la integración de agendas especificas.
Entre el auge de la democratización y los objetivos de la burocratización hay distancias importantes. La democratización es una via para abrir las oportunidades y los beneficios vedados a diversos núcleos ciudadanos, denota la posibilidad de revertir la vigencia de las desigualdades que lastiman la vida pública y permite que los actores sociales se reagrupen de manera significativa. La burocratización tiende a evitar los movimientos de la democratización porque la cultura que la define se orienta a la vigencia de relaciones que no promueven la equidad entre los ciudadanos. Entre los aparatos de poder y la burocratización hay vínculos que los definen por acrecentar el conservadurismo, no el cambio en favor de la vida social y política, por eso, la democratización se ha convertido en un medio que obliga a que los gobiernos revisen la eficacia de sus aparatos y al mismo tiempo emprender reformas institucionales y democráticas que los habilitan como sistemas creativos de respuesta.

Con el desarrollo de la economía de mercado también se han desarrollado los grandes aparatos de la burocracia gubernamental. El modo de atender los requerimientos materiales y sociales ha sido a través de complejas organizaciones- comisiones, firmas, ministerios, secretarias de Estado - que se encargan de la administración y la gestión públicas. En consecuencia, aumenta la esfera de lo gubernamental y lo administrativo hasta configurar una red de organismos que, por su grado de diversificación y capacidad polivalente, consiguen permear la base económica y social de la vida pública.

El Estado administrativo (Caiden, 1996: 70) es la organización más sobre- 
saliente de la sociedad moderna y con él, un estilo técnico, profesional y competente que se encarga de asegurar la dirección y la prosperidad de la sociedad. En este caso, los expertos - burocracia profesional-son los encargados de asegurar tanto la producción de la riqueza como el diseño de los sistemas que permiten la distribución de los beneficios sociales e individuales.

Un gobierno de expertos en el sentido de las capacidades burocráticas, es la divisa de los Estados administrativos. Sobre esta línea, la administración burocrática profesional (Weber 1999:117), entendida también como Administración Pública, es la que tiene a su cargo la atención y las respuestas que provienen de la sociedad, las empresas y los núcleos ciudadanos. Lo importante es que la racionalidad burocrática cumpla con las tareas que tiene a su cargo. La confianza en el cálculo y las operaciones administrativas son la base para asegurar que el cuerpo económico y social tenga rendimientos exitosos.

La destreza técnica, la pericia operativa y la capacidad procesual son los atributos del Estado administrativo, entendido como un Estado de recursos y capacidades ilimitados. En este sentido, el arte de administrar la vida económica y social consiste en el aprovechamiento $y$ la maximización de los recursos existentes. Consiste en que las decisiones y las acciones son fruto de la razón aplicada; que las mismas son motivo de posturas subjetivas, asi como de la racionalidad impecable, procedimental e instrumental.

La racionalidad burocrática (Weber, 1973: 30) no es un objetivo más, sino condición indispensable de vida para asegurar la consistencia de la administración del Estado. Entre el aparato burocrático y las necesidades estructurales de la economía de mercado se forman vínculos que se traducen en la existencia no siempre justificada de organizaciones que cumplen con las tareas de dirigir y administrar los procesos de la vida económica y social.

Lo distintivo del Estado administrativo es que se erige en el protagonista de la vida en sociedad. Ha tenido a su cargo las tareas de la planeación central; la programación de los recursos y la distribución de los beneficios sociales. En su desempeño se apoya en la administración pública hasta tener una presencia relevante que lo califica como Estado benefactor.

Su modo de obrar es centralizado, burocrático y gubernamentalizado, lo cual significa que se erige en el centro del quehacer social y político. El Estado administrativo es un Estado esencialmente burocrático, con tendencias a convertirse en un ejemplo de aura tecnocrática. Esto significa que su vigor institucional descansa en sí mismo, no en la construcción permanente de los consensos que son propios de la sociedad democrática. Concibe la importancia de la sociedad en términos económicos, pero en los aspectos de participación y deliberación no facilita condiciones idóneas para la expresión más acabada del pluralismo civico y político.

Ha gobernado con el apoyo de los cuerpos intermedios de la "sociedad civil"- sindicatos, asociaciones, partidos, asociaciones - sin reconocer el potencial y las capacidades cívicas y plurales de la misma. Su patrón de desempeño es el corporativismo y con ello, las tendencias 
democráticas no tuvieron cabida en los procesos que conducen al diseño, la formulación y la implementación de las politicas públicas. Ha gobernado más con la administración- racionalidad burocrática que con la democracia - racionalidad pública. Ha decidido más en las cúpulas y no con la participación ciudadana. Ha gobernado a través de grandes organizaciones; de nutridos procesos tecnoburocráticos y con formas que no siempre incluyen la presencia organizada y activa de los ciudadanos. Ha gobernado más con politicas y programas no equitativos; no con las asociaciones que demandan mayor participación y representación en la atención de los asuntos públicos. Ha gobernado invocando la eficiencia burocrática, no la eficiencia democrática. Asi, el Estado administrativo da vida a los Gobiernos omnipresentes que limitan la participación de los ciudadanos en los asuntos públicos. En consecuencia, ha impulsado a los gobiernos de los proyectos grandielocuentes, las soluciones certeras, los planteamientos precisos y las burocracias clientelares, las cuales se encargan, de asignar en nombre del "interés públi$\mathrm{co}^{\prime}$, los beneficios de orden económico y social.

\section{Espacio público y gobierno abierto}

Una de las consecuencias estructurales del Estado administrativo es la pérdida de confianza en las instituciones de gobierno, tal situación se desprende de que su capacidad de gobierno ha llegado a profundidades sin retorno. Esto no implica desconocer su papel necesario en favor de la sociedad industrial, pero tampoco es posible ocultar que su tarea de gobernar ocasiona los rendimientos decrecientes en su relación con la sociedad. La falla central del Estado administrativo se localiza en la filosofía, el sistema y las prácticas de la gestión gubernamental.

La obsolescencia gubernamental (Dror, 1994: 28) deviene del fin de una etapa caracterizada por la confianza excesiva en el tamaño de las instituciones burocráticas y en la concepción de que el Estado tenía autonomía creciente ante los grupos de interés y por tanto, tenía capacidad para dirigir en nombre del bien público. Este perfil del Estado es el causante de importantes fallas de gobierno. Una de ellas, haber establecido una distancia insalvable frente a los grupos ciudadanos y las asociaciones de particulares en lo relativo a la atención de las demandas. Otra falla es haber saturado el espacio de lo público con medidas, reglamentaciones, normas, organismos y acciones que inhiben a los agentes económicos y sociales. Una más, no haber valorado con oportunidad los costos que implica la existencia de una poderosa burocracia gubernamental, dado que llega a tener espacios amplios de maniobra para disponer del excedente económico, sin más límites que los recursos fiscales y presupuestales disponibles de manera ordinaria y extraordinaria.

No menos importante es haber convertido a la Administración Pública en un conjunto de estructuras y acciones que se alejan de los ciudadanos que desean tener participación en los procesos de la gestión pública. Tales fallas, combinadas con los desajustes económicos, la innovación tecnológica, las señales de la 
globalidad, la apertura de las economías, la crisis de los precios del petróleo y la incapacidad para remontar con eficacia la sobrecarga de las demandas sociales, provocan que la capacidad de gobierno propia del Estado administrativo, empiece a decrecer de manera importante en los años setenta y ochenta.

Con la politización de la administración pública se pierde el horizonte real de las capacidades de gobierno (Dror 1997: 49). No es casual que categorias de dudosa validez proliferen en el ambiente gubernamental, académico, social y político en relación a considerar la Administración Pública de acuerdo con las siguientes aseveraciones: "administración para el desarrollo; administración para el cambio social; administración integral para el desarrollo; administración del cambio planificado; administración para la planeación económica y administración para la riqueza". Estas aseveraciones dan cuenta de que la postura de gobierno ha sido más administrativista y más burocratizada; diluyendo asi, la dimensión política y el contenido público de la misma. En tales condiciones, los márgenes de gobernabilidad son frágiles y no alcanzan a detener el fracaso de las políticas orientadas a resaltar la administración sobre el gobierno; la administración sobre la política; la administración sobre las ventajas públicas. Toman delantera las posturas introspectivas del gobierno y las expectativas de que con la administración pública es posible alcanzar metas deseables, no tanto viables o factibles.

Con este panorama, el espacio público pierde iniciativas y oportunidades de realización, situación que incide para puntualizar que la capacidad de gobierno no puede continuar por la senda de los resultados insatisfactorios que el Estado administrativo genera. Se impone, por tanto, replantear el funcionamiento del Estados introduciendo los ajustes que permitan el reencuentro de los ciudadanos con el propio Estado. Así, modificar la óptica de gobierno es una de las tareas principales para evitar que la coraza burocrática y administrativa persista en el objetivo de "autonomizar" la gestión del Estado para que no sea instrumento cosificado de los "grupos dominantes" y que tampoco pierda su identidad " bonapartista" en favor de los más "desposeídos".

Abrit el gobierno a la sociedad y a los ciudadanos, es el propósito más importante para rehabilitar la gobernabilidad democrática. Abrir el gobierno al público y al espacio de lo público, es la premisa más relevante para que las políticas no sean fruto tecnocrático, sino producto democrático. Democratizar el gobierno implica democratizar la democracia en el sentido de que las políticas públicas contribuyen a que el acceso de los ciudadanos a los procesos de y en las políticas (Lasswell, 1971: 105) sea efectivo. No más gobiernos cerrados y excluyentes es la demanda más relevante en el espacio de lo público. No más gobiernos inequitativos e ineficientes, es el objetivo de los grupos ciudadanos que luchan a favor de que los espacios sociales sean devueltos a sus protagonistas después del largo periodo que da cauce a los gobiernos corporativos. No más gobiernos autoritarios ni más gobiernos faraónicos que usufructan los recursos y los bienes públicos, es la lucha constante que se desarrolla en el 
espacio público para que no subsista el impacto negativo de los gobiernos que deciden con ausencia de los ciudadanos.

El espacio público es un espacio que reivindica al ciudadano frente el gobierno; la democracia frente a la burocracia; lo común frente a lo clientelar; lo social frente a lo corporativo; la decisión compartida frente a las decisiones inducidas; la corresponsabilidad frente a los criterios unilaterales. El espacio público es el sitio de la pluralidad y la democratización; de los ciudadanos y la ciudadanización; de las aperturas y la democracia visualizada como un sistema de vida convenido, formalizado y corresponsable.

Por tanto, los gobiernos tienen como referente valorativo los elementos mencionados; más aun, los que tienen como propósito reivindicar el Estado ante la sociedad. La democratización de los gobiernos es la característica más significativa de la sociedad contemporánea, pues en conjunto reconoce y reivindica la importancia de la esfera individual, la interacción pública y la gestión social. La democratización es la clave para que los gobiernos sean abiertos y deliberantes; responsables y co-responsables; equitativos y eficientes. La democratización es consubstancial a la ampliación de la esfera pública y ésta fortalece la participación de los ciudadanos en los asuntos de interés compartido.

El espacio de lo público es el lugar donde la democracia ciudadana se manifiesta de manera policéntrica, es decir, donde existen centros que influyen en el quehacer polltico y social; son centros activos que reflejan cómo los valores, los intereses y las demandas de orden público se comportan de modo competitivo. El espacio público (Bresser, 1999: 88) es también un ámbito en el cual se desarrollan los procesos de concertación, gestión y participación que vinculan a los ciudadanos con las esieras de gobierno y con las diversas organizaciones que articulan sus intereses en términos de acciones que tienen impacto en la complejidad de la sociedad.

Lo público es un espacio en el cual los derechos cívicos y políticos se invocan para ejercerlos con base en las reglas que definen el funcionamiento de las instituciones públicas. El espacio público ha sido determinante para democratizar los gobiernos, esto significa que los gobiernos son más públicos, es decir, más de los ciudadanos y en ese sentido, es factible que la pluralidad de las demandas sea atendida con politicas variadas, no con políticas que intentan homologar contextos, actores y resultados. Las politicas para el espacio público no son burocráticas, sino políticas democráticas, es decir, gestadas, implementadas y evaluadas por los ciudadanos, no únicamente por las instancias de gobierno.

\section{Políticas ciudadanas y gobierno democrático}

Un resultado específico del ocaso del Estado administrativo y el vigor del espacio público, es que los gobiernos contemporáneos no deben obrar a la manera de cajas negras, sistemas cerrados o fórmulas rígidas de gestión institucional. El arte del buen gobierno no concibe a la sociedad con vacíos estructurales, es decir, con ciudadanos administrados y pasivos. Desde este mirador, los ciudadanos deben tener participación en los procesos 
políticos y en las políticas. Los gobiernos, por tanto, atienden demandas reales no anónimas; atienden demandas que surgen de intereses que, teniendo naturaleza privada, consiguen tener reconocimiento público.

El arte del buen gobierno no omite la importancia de los métodos idóneos para dar respuesta a los planteamientos ciudadanos y a las organizaciones civiles. Un método eficaz para gobernar es saber escuchar y saber deliberar. Otro método es que las demandas ciudadanas contribuyan a la definición de criterios y lineamientos susceptibles de traducirse en programas públicos. Un método más consiste en que los gobiernos formulen e implementen politicas ciudadanas. Las políticas ciudadanas son el destino último del buen gobierno. Son políticas nacidas en el espacio público; dirigidas a públicos especificos y tienen legitimidad pública. Son políticas que son objeto de deliberación; que han ingresado a la agenda institucional y son el resultado de interacciones significativas. Son políticas que tienen recursos asignados, apoyos organizativos, medios técnicos y respaldo institucional estimulado desde diversos espacios de la acción gubernamental.

Las políticas ciudadanas, a diferencia de las decisiones administrativas, tienen savia pública, mientras que éstas se construyen con la lógica de la racionalidad burocrática y los criterios incontrovertibles. Las políticas ciudadanas son fruto de la autoestima ciudadana la cual se fortalece cuando los gobiernos son abiertos, democráticos y equitativos. Las políticas ciudadanas son, en sentido genuino, políticas públicas; no hay antino- mia entre unas y otras; tampoco yuxtaposición o dilemas artificiales.

Las políticas públicas (Aguilar, 1992: 35) son de contenido ciudadano porque toman en cuenta al público interesado en la atención y solución de los asuntos que son de interés público. Son politicas que se diseñan no en el claroscuro del mundo administrativo; tampoco en las penumbras de los secretos de Estado. Son políticas que exigen discusión, intercambio de ideas, expresión de valores y argumentos convincentes para persuadir y convencer a diversos actores de la vida pública. Son políticas que implican participación, representación e interlocución para vincular las aportaciones ciudadanas con los recursos del gobierno.

Son políticas que se sustentan en reglas y procedimientos de carácter democrático (Riker, 1982: 6); en reglas y procedimientos que se reconocen como instituciones para articular las demandas y los intereses en competencia. Son politicas que se traducen en productos institucionales que son la expresión organizada de los ámbitos gubernamentales y los no gubernamentales. Son políticas que denotan la interacción ciudadanos - gobierno con base en el mundo propositivo de la democracia, en la cual la deliberación y la argumentación son elementos imprescindibles para el análisis, la cooperación y la acción pública.

Un gobierno es democrático no sólo por las formas constitucionales que le garantizan la legitimidad de origen, sino por los métodos que adopta para conducir. Como método de gobierno, las políticas públicas son incluyentes y participativas, tienen la ventaja de reconocer 
a los ciudadanos reales, no a los ciudadanos imaginarios; tampoco son proclives a las posturas de masa ni a la homogeneidad de realidades que son opuestas entre sí, no se proponen reivindicar condiciones de vida, sino seleccionar decisiones y cursos de acción que son factibles para que los problemas públicos sean motivo de solución y en su caso de resolución. Al vincular a los ciudadanos con el gobierno, contribuyen al ejercicio democrático del poder y a la ampliación de la esfera pública para evitar que los propios gobiernos incurran en excesos de autoridad y en la asignación discrecional de los recursos fiscales.

En un gobierno democrático, las políticas públicas son importantes para evaluar la legitimidad por resultados, es decir, el grado de eficacia, aceptación y reconocimiento que tienen los propios gobiernos y cómo son aceptados para atender y solucionar los problemas de interés común. En la óptica de las políticas públicas, los problemas que atienden los gobiernos no son indisolubles esto es, no carecen de solución en términos contextuales, fiscales, operativos, políticos y técnicos. Esto significa de acuerdo con la responsabilidad pública, que los gobiernos no se comprometen en la solución de problemas que trastocan la estructura básica de la sociedad- principios, instituciones derechos de propiedad, libertades, constitucionalidad -sino con problemas que se definen en razón de criterios factibles, pragmáticos y operativos. Además, desde el momento en que un problema se define como público, se enuncia y define el tipo de solución que requiere; esto significa que la definición y la solución de los problemas no son momentos separados, sino simultáneos. Se evita con ello, que el síndrome del decisionismo invada la lógica de los problemas públicos, pues el mismo privilegia en si misma la toma de decisiones, sin considerar el contexto del propio problema.

Por otra parte, una ventaja funcional de las políticas públicas es que sitúan la responsabilidad del gobierno de modo categórico y puntual. No son opción para ensayar planes irrealizables, proyectos quiméricos ni programas deseables. Tampoco son flexibles para soslayar los costos públicos de las decisiones que adoptan los gobiernos. Menos para propiciar, en nombre del "interés público", que los gobiernos llevan a cabo acciones que después tienen efectos negativos en la vida social y económica. Su contenido democrático no las distancia de su naturaleza pragmática. En este sentido, las políticas públicas forman parte del realismo político y la factibilidad pública; de los arreglos negociados y los consensos amplios; de los apoyos institucionales y los sistemas de corresponsabilidad social.

\section{Políticas públicas y gobernabilidad democrática}

El reencuentro de los ciudadanos y el gobierno es testimonio de que las políticas estatistas y los programas excesivamente gubernamentalizados no son funcionales para garantizar una vida pública consistente, productiva y equitativa. La omisión de los ciudadanos en los procesos de gobierno tiene consecuencias desfavorables. Ningún gobierno es efectivo si pretende realizar o realiza todo en 
la sociedad. Hay límites institucionales, operativos y fiscales para que los gobiernos no vuelvan a ser organizaciones magnificadas que generan costos negativos a los ciudadanos y la vida pública.

Soslayar las capacidades reales de los gobiernos compromete la existencia de los Estados y lesiona la base productiva de la vida social. Incidir en posturas pro gubernamentales cuando no hay justificación alguna, es cancelar el desarrollo individual y colectivo. Los gobiernos han pagado altos costos cuando sobrevaloran sus capacidades y recursos, en este caso, los desaciertos son asumidos por el público ciudadano y los errores de politica provocan pérdida de legitimidad. Corresponde a los gobiernos no incurrir en tesis y políticas que niegan su razón de ser y que únicamente ocasionan que la sociedad, los agentes económicos y los ciudadanos evalúen, con el voto de castigo, el desempeño no eficiente de las instituciones públicas.

En el presente, las acciones gubernamentales son motivo de supervisión y evaluación pública. No pueden evadir las exigencias de la opinión pública, en particular, de los grupos interesados en la formulación e implementación de las políticas. El hacer y el quehacer de los gobiemos es un asunto que implica deliberación pública, costos políticos y legitimidad social. Por eso, la responsabilidad y la eficacia del gobierno tienen que acreditarse con un desempeño relevante para que no sean motivo de sanción ciudadana - voto de castigo - el cual modifica la correlación de fuerzas en favor de los grupos opositores.

Los puntos medulares de la gobernabilidad democrática se refieren, sin duda, a la eficacia de las políticas públi- cas. La creación, maduración y consolidación de condiciones óptimas de vida se vincula con la gobernabilidad. Alude ésta, al conjunto de capacidades que se acreditan para que la sociedad viva con prosperidad, bienestar y justicia; sobre todo, la sociedad que se define por su contenido y alcance democrático. Gobernar la democracia significa orientar programas y políticas hacia el logro de metas compartidas; de metas que se definen de acuerdo a valores y demandas. Significa que la coexistencia de los opuestos exige destreza, sapiencia y pragmatismo para alcanzar ventajas económicas y sociales que sean compartidas.

En este caso, las políticas públicas son un medio para que la pluralidad de la sociedad sea atendida con políticas diferenciadas que contribuyan a la solución de los problemas públicos. Gobernar con las políticas implica responder a intereses ciudadanos; a planteamientos que tienen impacto en la arena de lo público y a las organizaciones que denotan interés en participar de manera corresponsable en los asuntos comunes. Gobernar con políticas evita que los recursos existentes sean asignados de acuerdo a necesidades reales y a grupos específicos, es decir, de grupos que tienen identidad civil y social. Gobernar con políticas abre los procesos de gestión para que los actores tengan la oportunidad de intervenir en las decisiones y acciones que se proyectan para la mejor atención de los problemas. Gobernar con políticas fortalece el espiritu de lo público, la autoestima de los ciudadanos y el carácter deliberativo de las instituciones que concurren en el abordaje y tratamiento de los asuntos de interés común. 
En consecuencia, la gobernabilidad democrática no es desideratum, sino una etapa del desarrollo institucional que se manifiesta por el conjunto de aptitudes que garantizan a la sociedad vivir con libertades públicas, democracia política y eficiencia continua. Esto significa que los gobiernos aplican políticas orientadas a promover la estabilidad, el crecimiento económico y el bienestar social. Significa que los agentes del mercado tienen un ambiente de certidumbre y seguridad a favor de los activos, las inversiones y el patrimonio privados.

Significa que la vida política es regulada por disposiciones que reconocen la competencia de los actores; que los conflictos son motivo de una institucionalización eficaz; que las instancias resolutivas cumplen con la adopción de las decisiones correspondiente; que el orden jurídico y político es capaz de funcionar para prevenir, sancionar y estimular la conducta de los ciudadanos y de más actores sociales. Significa que la calidad de vida- ingreso, bienestar, justicia, progreso y esperanza de vida-tiene resultados positivos y constantes que favorecen un clima de reconocimiento y aceptación hacia el sistema de instituciones que son responsables de que la sociedad viva bien, aspirando a vivir mejor.

La gobernabilidad democrática es el objetivo central de los sistemas políticos. Para ello, es importante que las instituciones (Ayala, 1999:62), los procedimientos, las normas y las politicas sean compatibles entre si para asegurar que el desempeño público sea eficiente, ordenado y consistente. De otro modo no es posible que la eficacia institucional sea la constante en la vida social y política. La gobernabilidad democrática se estructura en el conjunto de capacidades que tienen como objetivo garantizar la estabilidad y el desenvolvimiento funcional de la sociedad. Son capacidades que se producen y reproducen de manera importante con instrumentos y acciones encaminados a que los conflictos, los desajustes, las crisis y las transformaciones, no violenten el orden establecido ni los valores que se postulan de manera común.

La gobernabilidad (Arbós y Giner, 1996: 57) democrática es una etapa de vida que denota cómo las instituciones y los operadores tienen la capacidad para absorber problemas; para convertirlos en agenda y diseñar de acuerdo a su perfil, las soluciones factibles. El modo de abordar problemas y contratiempos es una faceta que pone a prueba la consistencia de las instituciones y la perspectiva que del gobiemo se tiene para contribuir a su racionalización. Asi, las políticas son la pieza esencial para los procesos de gobernación, ya que como productos del sistema político, influyen en las elecciones, las preferencias y las expectativas de los ciudadanos.

En este caso, las políticas de crecimiento y bienestar favorecen un ambiente de expectativas a cumplir. Las políticas de ajuste y estabilización no sólo corrigen problemas de fondo - déficit fiscal, endeudamiento, descapitalización- sino que racionalizan la satisfacción de las demandas sociales, porque su misión correctiva permite reordenar planes, objetivos, recursos y acciones. Las políticas de estímulo, promoción y regulación se encaminan a que los agentes económicos y 
sociales tengan bases de certidumbre para cumplir su responsabilidad pública. Las políticas del bienestar social tienen como meta que las condiciones reales de vida sean objeto de mejoría de acuerdo a las personas, las familias, las regiones y las comunidades. Las diversas políticas tienen una tarea específica a saber: conseguir de modo deliberado y consensado que la capacidad de respuesta de los sistemas políticos sea oportuna. El gobierno por políticas alude a capacidades múltiples que se aplican en una diversidad de condiciones, problemas, oportunidades y restricciones.

Sin duda, el contenido principal de la gobernabilidad democrática son las políticas públicas. Una y otra no son resultado de las formas constitucionales sino que responden más a los modos de gobernar, es decir, a cómo la dirección pública se sustenta en los aspectos de deliberación, coordinación y arreglo institucional. Responden a cómo la autoridad pública es capaz de concertar a los actores múltiples que concurren en la vida social. Responden a cómo se construyen los consensos y cómo se diluyen los disensos. El cómo es el punto principal para evaluar la eficacia de la gobernabilidad democrática.

En ningún caso el modo de gobernar es objeto de reglas únicas o procesos estandarizados. Cuando se gobierna la recta no es la línea más corta entre dos puntos. El modo de gobernar se manifiesta con estrategias; y éstas se relacionan con los protagonistas, los tiempos y las condiciones que concurren en la naturaleza de los problemas públicos. El modo de gobernar vincula a los ciudadanos y la autoridad con procesos complejos de de- cisión, deliberación y acuerdo. Tambiên con los tipos de desacuerdo que se originan cuando los valores y los objetivos no son coincidentes. En el modo de gobernar, los valores son esenciales para alcanzar o no acuerdos. De la misma manera, la definición de los objetivos depende de cómo los valores facilitan o no los acuerdos esenciales. Son los valores y los objetivos los que determinan el sentido y utilidad de las estrategias, las cuales, en materia de gobierno, nunca son rígidas ni unidimensionales, sino flexibles (Peters, 1996: 72) y multidimensionales.

Por tanto, la gobernabilidad democrática y las políticas públicas tienen conexión estructural. Una sin la otra son inexplicables. Son las políticas las que favorecen la vigencia de la gobernabilidad; y ésta alude a condiciones de vida que comprenden a las políticas como instrumentos que aportan elementos y resultados en favor del bien común. En un ambiente de gobernabilidad democrática, las preferencias electorales concurren en la formación de las políticas; influye también la presión de los grupos de interés; el estado que guarda la economía; las interacciones dadas entre las arenas de poder y las estructuras de decisión.

Las políticas no son únicamente decisiones de gobierno, sino productos institucionales que recorren distintos sitios para su elaboración, acción y evaluación. Las políticas se manifiestan en asuntos como la descentralización política y administrativa; las acciones fiscales; los procesos monetarios; el impulso a la ciencia y la tecnologia; la aplicación de los programas educativos; la atención a la salud; el aliento al comercio y el cumplimiento de la legislación laboral entre 
otros aspectos. Su alcance funcional refleja el modo de gobernar y cómo se crean situaciones que favorecen el comportamiento de la dirección pública.

En el caso de la gobernabilidad, es importante destacar que el pluralismo democrático- ideas, organización, proyectos, opinión ciudadana, partidos políticos y grupos sociales - es lo que nutre la complejidad política e institucional. Su dinámica es intensa, competitiva e interdependiente. Por eso, la gobernabilidad no es un asunto en sí del gobierno, sino que se refiere a cómo se producen las capacidades que garantizan el desempeño ef:caz de los sistemas políticos.

En este sentido, las políticas públicas son elemento importante en el quehacer de la política, dado que con ellas se adoptan decisiones y se llevan a cabo acciones que provocan reacomodos en las estructuras del poder social, al propiciar que los grupos de interés tengan ventajas unos frente a otros. De igual manera, la política (politics) es factor determinante en el desempeño de las políticas, porque la cadena de intersubjetividades que la integran, se traduce en la expresión de intereses y en la influencia que tienen para ganar sitios en los procesos decisivos de la acción pública.

Los vínculos entre la política y las políticas son elemento puntual en la calidad de la gobernabilidad democrática. La conexión funcional entre una y otra es importante para entender a los gobiernos como organizaciones complejas que no deciden sin pesos y contrapesos; sin presiones y contrapresiones; sin fuerzas y contrafuerzas. La producción de la gobernabilidad- consensos (Buchanan y Tu- llock 1993:70) estabilidad dinámica, institucionalidad, legitimidad política y administrativa, bienestar efectivo - alude a estrategias, capacidades, recursos y tiempos que se enlazan tomando en cuenta el efecto multiplicador de la política y las políticas.

Desde la óptica de las políticas, la gobernabilidad se construye a través de productos institucionales que se originan, elaboran e implementan en los diversos sitios de la vida pública donde hay actores centrales que participan en el juego organizacional e institucional que favorece o no su ángulo pragmático. Sin embargo, la efectividad de las políticas no se ciñe a consideraciones de carácter técni$c o$, sino que dependen las mismas del contexto en que se proclaman. Esto significa que las políticas públicas no están exentas de presiones propias y ajenas, sino que a pesar de las mismas, tienen que contribuir al mejor rendimiento de las instituciones públicas, dado que son el punto nodal para evitar que la gobernabilidad democrática tenga quebrantos o crisis que pueden dislocar la relación estructural, necesaria e imprescindible de los espacios privado, público, político y social.

\section{Conclusión}

En un mundo de tendencias democráticas acrecentadas, las políticas públicas constituyen un recurso idóneo para que el modo de gobernar sea incluyente, participativo y equitativo. Valoradas como instrumentos del quehacer abierto y deliberativo de los gobiernos, permiten que los ciudadanos participen directa- 
mente en las fases que sustentan su operación y efectividad. A diferencia de los grandes aparatos de poder, favorecen el vínculo directo entre los ciudadanos y las autoridades públicas. Contribuyen de esta manera a que la autoestima de los ciudadanos sea piedra de toque en los procesos de la vida institucional, al reivindicar sus capacidades, derechos y responsabilidades adormecidos con la práctica densa y dilatada de las acciones estatales.

Las políticas públicas no son más gobierno ni más Estado; por el contrario, contribuyen a limitar su tamaño innecesario y a mejorar la calidad de su desempeño con base en la aportación de los ciudadanos y en las estructuras de decisión que canalizan las demandas y los intereses que definen su núcleo de identidad. Las políticas públicas tienen como puntos básicos la eficacia de las decisiones, los procesos y las acciones, no tanto la dimensión organizativa y burocrática del gobierno. Son el medio para que los ciudadanos organizados tengan presencia y representación en los procesos emprendidos para democratizar el gobierno. No son instrumento avasallador del gobierno para decidir e implementar, sino un método que contribuye a que la relación de los ciudadanos y el propio gobierno sea activa, directa y puntual. No más interlocutores innecesarios; no más estructuras de intermediación; no más relaciones clientelares; no más decisiones de cenáculo burocrático, son elementos que pueden diluirse con una perspectiva amplia y emprendedora de la vida pública. Reivindicar lo público con las políticas significa que los ciudadanos tienen participación en la operación del gobiemo, esto es, en los procesos que conllevan al ejercicio democrático de la dirección pública.

La reivindicación de lo público da paso a la ciudadanización para que los gobiernos dejen atrás las valoraciones ideologizadas y politizadas que pretenden justificar su expansión sin haber motivo alguno. Reivindicar to público da oportunidad para que el reencuentro ciudadanos - gobierno sea sobre bases diáfanas y relaciones equitativas que son consecuentes con los valores y principios de la organización democrática del poder. Reivindicar lo público es procurar que lo gubernamental sea transparente y democrático en momentos que la participación ciudadana reclama para sí, los sitios que le corresponden; en este caso, los relacionados con los procesos de las políticas. Reivindicar lo público es reconocer que las políticas articulan intereses, sin soslayar que su negociación es compleja e intensa. Reivindicar lo público significa que las políticas le devuelven a los ciudadanos la oportunidad de ejercer sus derechos al incorporarlos a los procesos de la decisión y la acción públicas.

El ámbito institucional de las políticas no es algo dado. Es y ha sido motivo de construcción intersubjetiva- actores, intereses, percepción y valores -para regular condiciones objetivas de vida- funcionamiento del régimen político - que tienen su fundamento en la vida pública. Convergen en el mismo- ámbito institucional - una pluralidad de intereses, actores, organizaciones y valores que denotan que la estructuración de las políticas se inscribe en los diversos espacios del régimen político -normas, procedimientos, reglas que encauzan la relación de los ciudadanos y el gobierno - que concu- 
rren en los múltiples tramos del quehacer institucional. El impacto de las políticas se relaciona con el grado de gobierno. Éste significa que las capacidades institucionales aseguran la cohesión del sistema político; que los procesos de gestión pública ordenan, encauzan y aplican politicas diversas; que la eficacia en la operación del gobierno es incuestionable; que la estabilidad social y política es resultado de interacciones que son reguladas a través de la agenda institucional.

Desde el grado de gobierno - institucionalización eficaz de los problemas y abordaje efectivo de las restricciones -; las políticas públicas son ideas que se traducen en proyectos y éstos en acciones, lo cual significa que a pesar de las restricciones sociales, políticas y económicas, las políticas denotan las rutas diversas- modo de gobernar - trazadas para formular alternativas de solución y resolución a los asuntos públicos. El gobierno por políticas y de las políticas alude a las demandas en competencia, los intereses en juego y a la necesidad de convertir en programas públicos, requerimientos privados que son aceptados por la opinión pública para que sean motivo de tratamiento y respuesta institucional.

De este modo, las políticas son decisiones, proposiciones y operaciones que dan vida al modo de gobernar los problemas públicos, mismos que no tienen solución única, duradera y concluyente. El carácter "no doméstico ni inercial" de los problemas públicos da cuenta de cómo el funcionamiento del régimen político es fundamental para considerar que las politicas no son arreglos simples, sino que responden a contextos, procesos y acuerdos en los cuales la interacción es la variable compleja que orienta, modula y determina por qué los gobiernos deciden e implementan de un modo y no de otro; por qué los gobiernos modifican prioridades, programas y recursos; por qué los gobiernos hacen y rehacen las políticas; por qué los gobiernos cumplen objetivos y por qué no; por qué los gobiernos no logran cumplir exhaustivamente con lo ofrecido a los ciudadanos; por qué en los gobiernos lo importante no es la predecisión sino los momentos de posdesición (legitimidad por resultados).

Como estrategia de gobierno, las politicas públicas favorecen relaciones de cooperación entre los actores que compiten para ingresar a la agenda institucional y a la asignación de los recursos fiscales. El gobierno por políticas reconoce la pluralidad y el carácter competitivo de las demandas. Toma en cuenta los contextos de intensidad ciudadana y asume la tarea de valorar, decidir e implementar la viabilidad y la factibilidad de los programas públicos. En condiciones donde el pluralismo democrático es el atributo de las sociedades abiertas, las políticas públicas tienen la ventaja de articular, sumar y consolidar la cooperación de los ciudadanos para que la acción de gobierno sea productiva y efectiva.

\section{Bibliografía citada}

Aguilar Villanueva F. Luis (1992) Estudio Introductorio a la Antologia 1 El estudio de las políticas pủblicas, Miguel Angel Porrúa. México.

Arbós Xavier y Salvador Giner (1996) La gobernabilidad. Ciudadania y democracia en la encrucijada mundial. Siglos XX| Editores. Madrid. 
Ayala Espino José (1999), Instituciones y economia. Una introducción al institucionalismo económico, Fondo de Cultura Económica. México.

Bresser Pereira, Luiz Carlos (1999), Reforma del Estado para la cludadania Editorial Universitaria de Buenos Aires y Centro Latinoamericano de Administración para el Desarrollo. Eudeba. Buenos Aires.

Buchanan, J. M. y G. Tullock (1993) The calculus of consent, Ann Arbor University of Michigan Press. Michigan USA.

Caiden, Gerald, (1996) "La revitalización de la Administración Pública", en Revista de Administración Pública, Instituto Nacional de Administración Pública, núm. 80 . México.

Dror, Yehezkel, (1994), La capacidad de gobernar, Fondo de Cultura Económica. México.

Dror, Yehezkel, (1997), "Mejoramiento de la capacidad para gobernar en América Latina", en, Revista Aeforma y Democracia, Centro Latinoamericano de Administración para el Desarrollo, núm. 7. Caracas.
Giddens Anthony (1993) Crisis de la modernidad, Alianza Editorial. Madrid.

Lasswell, D. Harold (1971), "La concepción emergente de las ciencias de políticas" en, El estudio de las politicas pública Antología 1, coordinada por Luis F. Aguilar Villanueva, Miguel Angel Porrúa. México.

Peters Guy (1996), The future Governing. Four Emerging Models, University Press of Kansas.USA.

Popper, R. Karl (1993), La sociedad abierta y sus enemigos, Editorial Taurus. Madrid.

Riker, H. W. (1982), Libersalism Against Populism, A confrontation between the theory of Social Choice, University of Rochester.USA.

Weber, Max (1973) "La política como vocación", en El político y el clentífico, Alianza Editorial. Madrid.

Weber, Max (1999) "La burocracia" en Clásicos de la Administración Pública, Estudio Introductorio de Mario Martinez Siva, Colegio Nacional de Administración Pública y Fondo de Cultura Económica. México. 